\title{
The Effects of Children's Friendship Training on Social Skills and Quality of Play among Children with Autism Spectrum Disorder
}

\author{
Horng Shen Ellipse Goh, Samsilah Roslan*, Ezza Mad Baguri \& Sing Yee Ong \\ University Putra Malaysia, Selangor, Malaysia \\ https://orcid.org/0000-0001-8559-9339 \\ https://orcid.org/0000-0003-1795-1606 \\ https:// orcid.org/0000-0002-5878-9003 \\ https://orcid.org/0000-0002-5741-6213 \\ Siaw Yan Li \\ University of Malaya, Malaysia \\ https://orcid.org/0000-0002-2815-4867
}

\begin{abstract}
Among the challenges faced by children with Autism Spectrum Disorder (ASD) involves developing social skills and building quality friendship through social activities, interactions and playing games. The purpose of this study was to find out the effect of Children's Friendship Training (CFT) on social skills among children with ASD. Utilising the quasi-experimental design of one-group-pretest-posttest study, this research was conducted on 40 children aged 7 to 12 years in the Klang Valley, Malaysia. The intervention lasted for 12 weeks and involved both the children with ASD and their parents. Data was collected twice for pretest and post-test scores using two sets of questionnaires, Social Skills Rating Scale (SSRS) and Quality of Play Questionnaire (QPQ). Descriptive and inferential statistical tools were used to analyse the data. The findings indicated that there were significant increase in the social skills of children with ASD after the intervention, based on both the teachers' $(t(30)=-6.298, p=.000)$ and parents',$(t(30)=-8.266, p=.000)$ evaluations. All the three subscales of Quality of Play also showed significant differences after the intervention, with significant decrease in conflict, $(t(30)=3.949, p=.000)$ and disengagement $(M=5.52, S D=1.93),(t(30)=$ $3.474, p=.002)$, and significant increase in engagement, $(t(30)=-4.892, p$ $=.000$ ). In conclusion, CFT effects were significant in enhancing social skills and quality of play among children with ASD. As social skills are very much related to social acceptance and ultimately self-concept and self-esteem, the potentials of CFT in overcoming social skill issues among children with or without learning disabilities should be explored further.
\end{abstract}

Keywords: Children's Friendship Training (CFT); Autism Spectrum Disorder (ASD); social skills; quality of play; problem behavior 


\section{Introduction}

Autism is getting more attention and concern (White et al., 2010) in Malaysia since the 20-century (Amar, 2008). Researches, prevention, and intervention programs had been carried out and developed (Alallawi et al., 2020; Morelli et al., 2015; Weiss \& Harris, 2001). This is due to the prominent concerns towards the social and communication skills in ASD children (Petrina et al., 2014; Scheeren et al., 2020). Children with ASD viewed the concept of friendship differently from the way other children perceive it. The understanding of the friendship of children with ASD tended to focus more on companionship rather than intimacy or affection. The ratings of perceived friendship quality also showed a huge difference in how children with ASD rated their friendship in comparison to other children. Children with ASD seemed to rate low on their best friendships based on dimensions such as companionship, helpfulness, security, and closeness (Calder et al., 2013).

Besides, children with ASD benefit greatly from having one or two best friends. It helps them to handle life events better (Yamada et al., 2020). A study showed friendship correlated positively with self-esteem and negatively with anxiety or depressive symptoms. However, $50 \%$ of adolescents with ASD did not have a friend hence they did not experience the benefits (Schohl et al., 2014). Children without ASD may develop a friendship that is already present in the first two years of life. That is why infants and toddlers exhibit behaviours that show preferences towards some playmates and not others (Chang et al., 2016). On the other hand, children with ASD face difficulties in building friendships (Skafle et al., 2020). In the early years, they tend to isolate themselves and do not try to interact or play with others. This becomes a problem in later years because they do not develop the ability to read social cues and find it challenging to recognize social faux pas (Baron-Cohen, S., O'Riordan, M., Stone, V., Jones, R. \& Plaisted, 1999). Children with ASD have a lower rate of prosocial behaviour compared with typically developing children (Dunfield et al., 2019). They also facing problem in social interaction (Mazza et al., 2017) which decreases their communication skill and social engagement in building friendship.

Many intervention and social skills training programs were designed to enhance the general acquisition of discrete social skills. Unfortunately, there is a lack of intervention programs that focus on promoting the social competency of autistic children (Bellini \& Akullian, 2007). Previous studies limited their focus on skills deficit model rather than social intervention on building child's social strengths (Varley et et.al., 2019). Even though there was evidence in improving social competence but there was limitation on significant finding among children aged below 15 years old. Besides that, other interventions did not specifically address important key variables such as the internal validity, inter-rater agreement, and treatment reliability of the study (Fombonne, 2009). With regards to children with ASD, some of the main domains affected by ASD include social, behavioural, and language developments. The severity of ASD symptoms differs from one person to another. However, impairment in social skills is the key feature of ASD, and children with ASD often display what is normally interpreted as limited functionalities in terms of language and intelligence (Tse et al., 2007). One of the 
biggest impairments in ASD is poor social interaction skills and it does not fade away during childhood or adolescence. Those high functioning ASD children may portray extreme characteristics of the disability during adolescence (White et al., 2010).

Autism is a neurodevelopmental disorder that is present with several behavioural problems. According to Crone and Mehta (2016), some of the most common behaviour problems exhibited by children with ASD are tantrums $(76 \%)$, aggression $(56 \%)$, stereotyped behaviours $(14 \%)$, and self-injury $(11 \%)$. Another big challenge for children with ASD is to be involved in quality social play, which is an important milestone in social development (Ray-Kaeser, et al., 2017; Salter et al., 2016). Children normally develop their creativity through play and this helps them improve their imagination, physical, cognitive, emotional, and social skills (Clark, 2016; Pop, Pintea, Vanderborght, \& David, 2014). It is, however, a challenge for children with ASD to engage in a symbolic or pretend play because they are not equipped with the skills it requires. Compared to others, children with ASD only take part in a play that is not as elaborate or as diverse as it would be for those without ASD (Pop, Pintea, Vanderborght \& David, 2014).

Although using the language for social communication is a struggle for individuals with high functioning ASD, they often perform well in terms of the structural and content aspect of language. However, they tend to ignore the needs of their partner in conversation and seem to not be sensitive to the listeners' interest. When in conversation they often fail to provide their partners with new or relevant information. Apart from that, they also tend to use unusual prosodic features and language that are too formal and are out of context. These tendencies cause misinterpretation of social cues which result in an exchange of inaccurate messages through communication (Kent-Walsh et al., 2015).

It is also observed that children with ASD lack social skills that restrict them from communicating effectively (Demopoulos et al., 2016). This hampers their ability to construct bonds with those around them causing them to struggle in developing or maintaining meaningful relationships. Social pragmatics, regulation, expression, and understanding of emotions are all challenging tasks for children with ASD. Their shortfalls in these areas often result in rejection from peers causing them to experience isolation (Locke et al., 2014). In the course of their development, individuals are usually required to acquire a certain degree of peer etiquette to create and maintain a friendship (Frankel et al., 2010). Flavell and Miller (1998) mentioned communication and social skills as the most important assignments in our life and they do not necessarily improve with mental age. Unfortunately, most of the ASD children are struggling to generate and sustain a positive interaction among peers (Frankel et al., 2010) even for high functioning ASD children (Bauminger et al., 2003; Bauminger et al., 2004). The impairment caused by poor social skills may become more prominent over time along with the demands of the school-aged period (White et al., 2007). 
Therefore, this study aims to study the effects of the Children's Friendship Training (CFT) in enhancing the social skills and quality of play in children with ASD between 7 to 12 years old. The research questions included:

1) Is Children's Friendship Training effective in enhancing the social skills of children with ASD between 7 to 12 years old?

2) Is Children's Friendship Training effective in reducing the problem behaviour of children with ASD between 7 to 12 years old?

3) Is Children's Friendship Training effective in enhancing the quality of play of children with ASD between 7 to 12 years old?

\section{Literature Review}

Past researches indicated that placing high functioning ASD children in a mainstream class will enhance the complexity of their play and reduce the possibility of having activities alone (Adams et al., 2017; Frankel et al., 2010; Sigman \& Ruskin, 1999). However, without additional treatment, it shows no improvement in their social interaction frequency even though the ASD child studied together with mainstream students (Frankel et al., 2010; McConnell, 2002; Skafle et al., 2020; White et al., 2007). There are many social skills intervention programs available and often applied in clinical practice nowadays, but not all of them are evidence-based interventions (Mandelberg et al., 2014). The empirical evidence regarding the effectiveness of these social skill intervention programs for children with ASD is still insufficient (Dekker et al., 2014; Kazemi \& Abolghasemi, 2019). In addition to that, there is also a very limited number of social skills interventions involving parents and teachers (Dekker et al., 2014).

A review of the literature has also shown that there is insufficient research to determine the most effective method for social skills building (Adams et al., 2017; White et al., 2007). There is also a limited number of researches that used groupbased social skills training approaches for children with ASD. A review of past social skill interventions indicated that several methodological issues were not scientifically addressed. These include internal validity, inter-rater agreement, and treatment reliability (Fombonne, 2009). In general, research has found that better social skills tend to contribute to positive peer interaction. This positive peer interaction will then provide children with an opportunity to learn positive behaviour through peer modelling. This will in turn help children to gain positive support and acceptance from their peers and friends. Unfortunately, studies also showed that the majority of children lack the social and academic skills needed when they enter kindergarten (Montroy et al., 2014).

Several studies reported on social skills interventions for children with ASD such as social skill training (SST). Schools and clinical practices are known to have placed great emphasis on specific group-based SST as a part of their treatment. One study, utilizing the randomized controlled trial method was conducted on 120 participants with ASD aged between 10-12 years and with an intelligent quotient level of above 80 . The participants were randomly assigned to three conditions; SST, SST with parent and teacher involvement, and care-as-usual. This training spanning across 15 weekly sessions helped children with ASD to develop skills such as making eye contact, starting a conversation, and cooperation. In 
conclusion, the research highlighted the need to carry out more studies on the effectiveness of this kind of training or intervention (Dekker et al., 2014).

In addition to this, Mandelberg and his colleagues had run research to examine the long-term outcomes of the Children's Friendship Training (CFT) effectiveness on children with ASD who had gone through CFT one to five years earlier. The results proved that the ASD children who participated in the previous CFT program showed some noticeable changes. They indicated significantly more playdates, less play conflict among peers and friends, a significant improvement in parent-reported social skills and problem behaviours, and revealed a slightly significant decrease in loneliness when compared to when they first joined the CFT program ( Frankel, et al., 2014).

Frankel and his colleagues continued their research on the effects of Children's Friendship Training. They also designed the Program for the Education and Enrichment of Relational Skills (PEERS) treatment which adapted the core features of CFT. PEES focused on adolescents with Autism Spectrum Disorder (Laugeson et al., 2012). Besides, there was another study conducted using PEERS on young adults with ASD. The results indicated that there was an overall improvement in social skills reported by the caregivers in the treatment group. Specifically, it was found that the participants showed an increase in cooperative social behaviour with peers and caregivers, social assertiveness, and self-control after receiving the treatment. It also significantly decrease in social anxiety (Hill et al., 2017). Furthermore, there was a significant improvement reported in their overall social responsiveness. This study suggested they may go through positive development (Gantman et al., 2012) in the ability to make sense and predict other people's behaviour (Hale \& Tager-Flusberg, 2005).

Another study to evaluate the effects of the 14-weeks PEERS program on social skills and social anxiety for 58 adolescents with high functioning ASD also provided interesting results. The results indicated that the experimental treatment group showed evidence of PEERS efficacy in which the participants showed gained knowledge of PEERS concepts and friendship skills. The experimental treatment group also showed an increase in hosted and invited get-togethers. It is interesting to note that a significant increase in hosted get-togethers was found in the original PEERS study, but they did not find a significant increase in invited get-togethers (Schohl et al., 2014). Reichow et al. (2012) conducted a study involving a meta-analysis on the randomized control trials of social skills among people with ASD. The study found that there was some evidence showing the social skills groups improved in overall social competence and friendship quality. However, the findings indicated that there was no difference between the treatment and control groups about emotional recognition. Nevertheless, Reichow et al. (2012) suggested that more research on ASD children social skills is necessary, especially data of their improvement in their quality of life after intervention programs.

CFT has also applied the concept of Behaviour Analytic Theory of Autism in order to reduce problem behaviours. One of the common misunderstandings on the 
children with Autism was their problem behaviours were unchangeable as they were born with it. However, Behaviour Analytic Theorist believe that it is possible to reduce children's problem behaviours if they were positioned in appropriate environments (Lovaas et al., 1989). Moreover, Behaviour Analytic Theorist argued that problem behaviour of the children with Autism might be due to behaviour deficits, but not central deficits. If the therapists are able to enlist parents as part of the treatment and resolve these behaviour deficits, it will eventually lead to a broad improvement (Lovaas et al., 1973). Thus, CFT aimed to create the suitable environments for the children with Autism to resolve their behaviour deficits, which ultimately reduce their problem behaviours.

Another major theory that underlies CFT is Piaget's theory of cognitive development, specifically in promoting children's quality of play. As mentioned previously, children need to go through different cognitive development stages to grow, and human has the inborn drives to develop their cognition by exploration and mastery of the environment and the development of selfconfidence (Cook \& Cook, 2009; Woolfolk, 2015). Assimilation and accommodation, two central concepts of Piaget's Theory, were significant in promoting quality of play. In the preoperational period, the children will start to use pretend play, such as taking the roles of parents, in their learning process. Through the pretend play, they learn new information (assimilation) and adjust the knowledge scheme through interaction (accommodation). By offering the platform of CFT as a safe place for exploration and mastery of the skills, the children would able to enhance their quality of play which is significant for their cognitive development.

In short, Vygotsky's Zone of Proximal Development, Behaviour Analytic Theory of Autism and Piaget's Theory of Cognitive Development, were the main theories underpinning this study which is focusing on social skill, problem behaviour and quality of play (Figure 1). 
Figure 1: Theoretical Framework of this Study

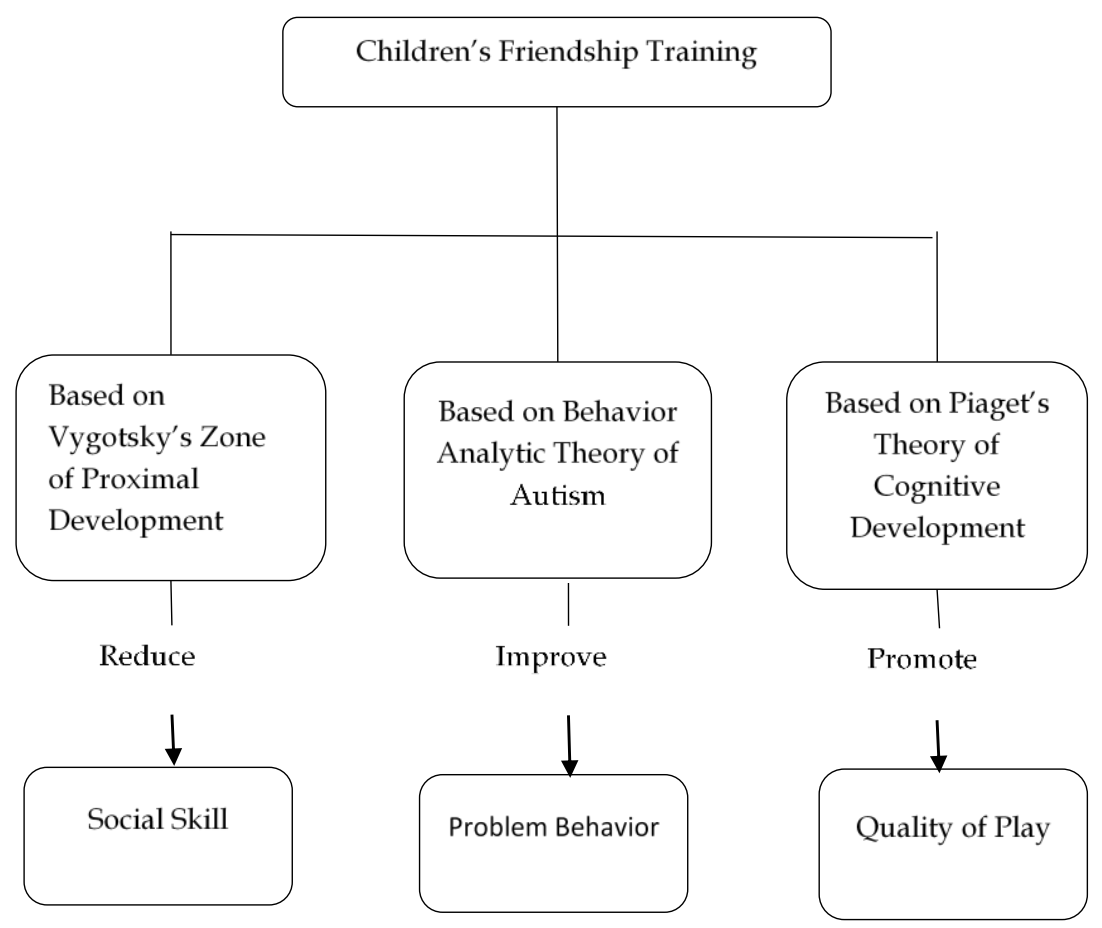

\section{Method}

\subsection{Design}

This research utilizes the quasi-experimental method of one-group pretestposttest design. One-group pretest-posttest design is adopted as it has widespread usage in applied field settings and can help enhance the internal validity of the study. The participants went through a 12-weeks continuous CFT (intervention programs). Each session took one hour and thirty minutes. CFT focuses on a few targeted skills such as social connection formation with the aid of parents, trading information with peers, peer entry into a group of children already at play, play dates, and conflict evasion and deliberation. These skills are taught using behavioural rehearsal intervention as one of the methods (Laugeson et al., 2007). 
Figure 2: Research Design of the Study

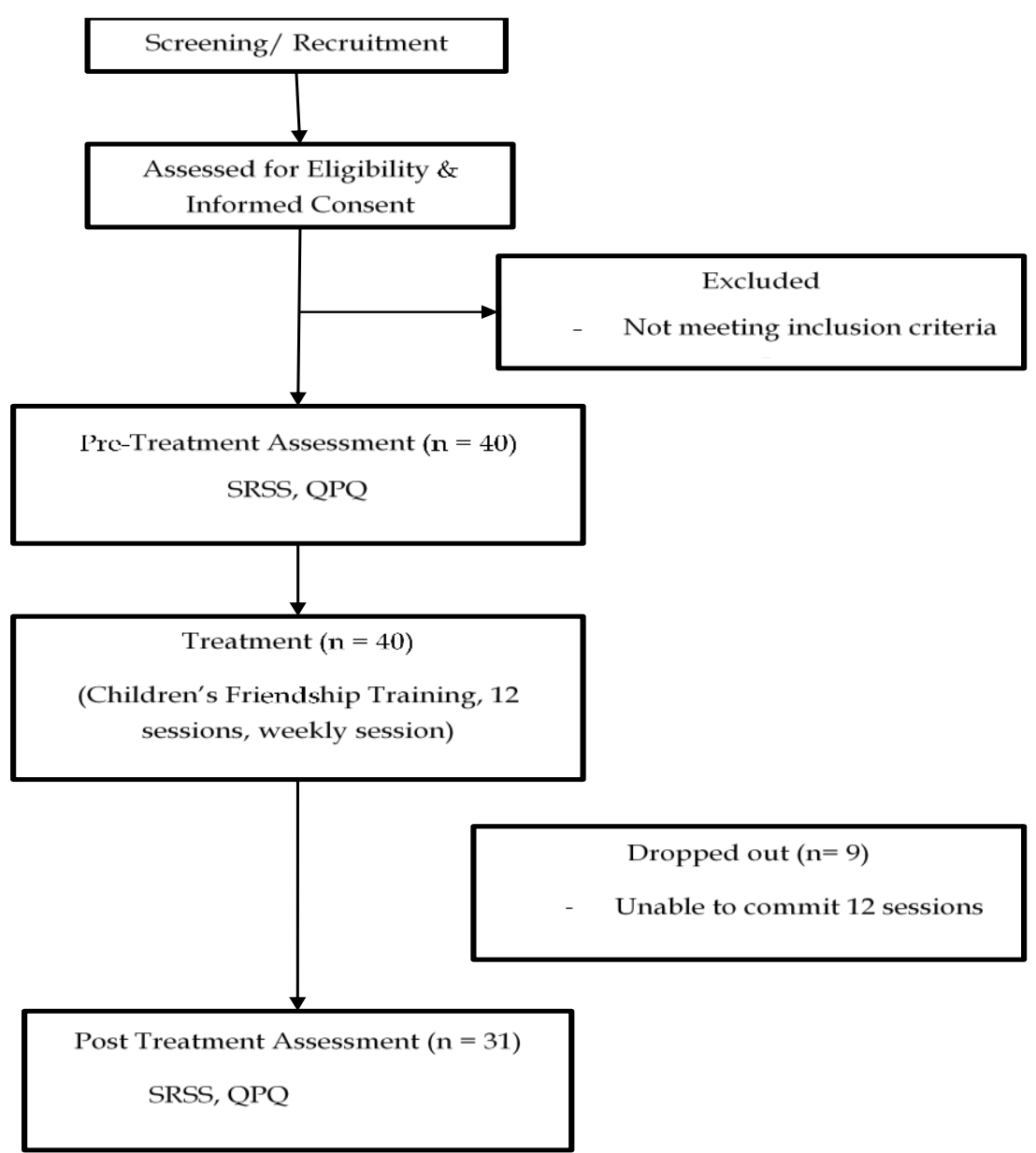

SRSS - Social Skills Rating System

QPQ- Quality of Play Questionnaire

\subsection{Procedure}

The CFT program involved three stages. In the first stage, a therapist who was experienced in teaching children with special needs conducted the CFT activities with the ASD children according to the CFT module. At the same time, the parent(s) of the ASD children were engaged in a separate parent group where they went through several activities to help them follow through with the program at home. In the second stage, parents provided additional scaffolding for their child. Parents were informed and briefed by other therapists on the appropriate ways to guide their child to practice the given homework at home. This was to ensure the children practice the learned specific social skills and had appropriate guidance and encouragement from the parents. This stage is the most crucial, as the children with ASD might have difficulties in making friends on their own. Hence, proper guidance from the parents was very important as they planned, set up, and arranged the playdates, or took their children to the 
playground to practice the learned skills. They were continuously reminded of the importance of unconditional positive regard and encouragement. In the final stage, the children would practice the learned social skills on their own in real-life settings such as at home, schools, and others.

Specifically, the children's sessions consisted of briefings on session rules, and activities structured along themes. Themes included appropriate places and times to make friends, two-way conversations, "slipping in", levels of disclosure and appropriate ways to react when turned down. Also, themes such as rules of good sport, rules of the good sport for ending games and rules of a good host. Besides that, the sessions also included themes to help them with social situations such as making fun of the tease, "unjust" adult accusations, rules of good winners and ways to stay out of the fight. The final session was the graduation party.

There were four sections in the children's session; homework review, didactic, real play, and homework assignment. At the beginning of the session, children were required to talk on the progress of their given homework. Then, the lesson of the day would be taught to the children using the Socratic Method. The concept of the Socratic Method involved allowing the children to provide the rules for a situation so that it appeared as if they were the ones making the rules. The researcher used the Socratic Method to make the children's learning more active and livelier and to encourage them to learn from each other. This would allow the children to feel more competent as they suggested the rules themselves. The children were then required to practice the learned knowledge and skills in roleplays with other participants. Reinforcements such as stars and tokens as well as punishment methods (timeouts) were applied throughout the session as forms of behavioural modification (Nevin \& Grace, 2000). In addition, homework assignments were given at the end of the sessions. Parents' were given handouts to outline the activities of every session. In the first parents' CFT session, goals were set and introduced to the parents to ensure everyone had a clear vision of the expected direction to achieve. Limitations of the intervention were also briefed to ensure that parents do not have unrealistic expectations of the outcomes of the program.

In the second CFT session, parents were required to practice their active listening skills. There were discussions on how to listen to their child's sharing of the activities done during the day and the children's phone conversations with their peers if there were any. The objective was to assist parents on how to encourage their children to have two-way conversations. In the third session, parents were required to help gather resources for their children to make friends. The aim was to assist their children in accomplishing their assignments related to improving their social skills in making friends. The fourth and fifth sessions were "slipping in" where parents learned how children make new acquaintances. They were then required to practice the "slipping in" skills with their children.

"Inside games" was the topic of the sixth session where parents were asked to identify appropriate and inappropriate toys or indoor games for their children to play in a group. Parents were also expected to assist their children to search for potential best friends. In the seventh session, the playdates topic was introduced 
to parents. They were required to discuss and come to an agreement on a suitable time for their children to make phone calls to the parent of the child who was going to be invited over for the playdates. In the eighth session, parents practiced with their children on effective ways to resist being teased by peers. This included turning the tease into something fun and humorous. The ninth session was a continuity of the eighth session where parents practiced with the children the appropriate ways to respond to adult injustice accusations. In the tenth session, parents learned about the gender differences in play and friendship patterns to adjust to the children's expectations of what might happen. This was followed by learning about ways to help their children to avoid and reduce physical fights with others in the eleventh session. The last session was a graduation party where parents learned about the follow-up assignments after the intervention ended. They were reminded to ensure their children to keep practicing all the learned skills and tasks in CFT.

In the final stage, the children in this group will practice the social skills learned while encountering social challenges in the real life setting like a house, school, and others. It is postulated that at this stage, the social skills, problem behaviour, and quality of play of the children with ASD will be influenced by the CFT program (Figure 3).

Figure 3: CFT Program Procedures

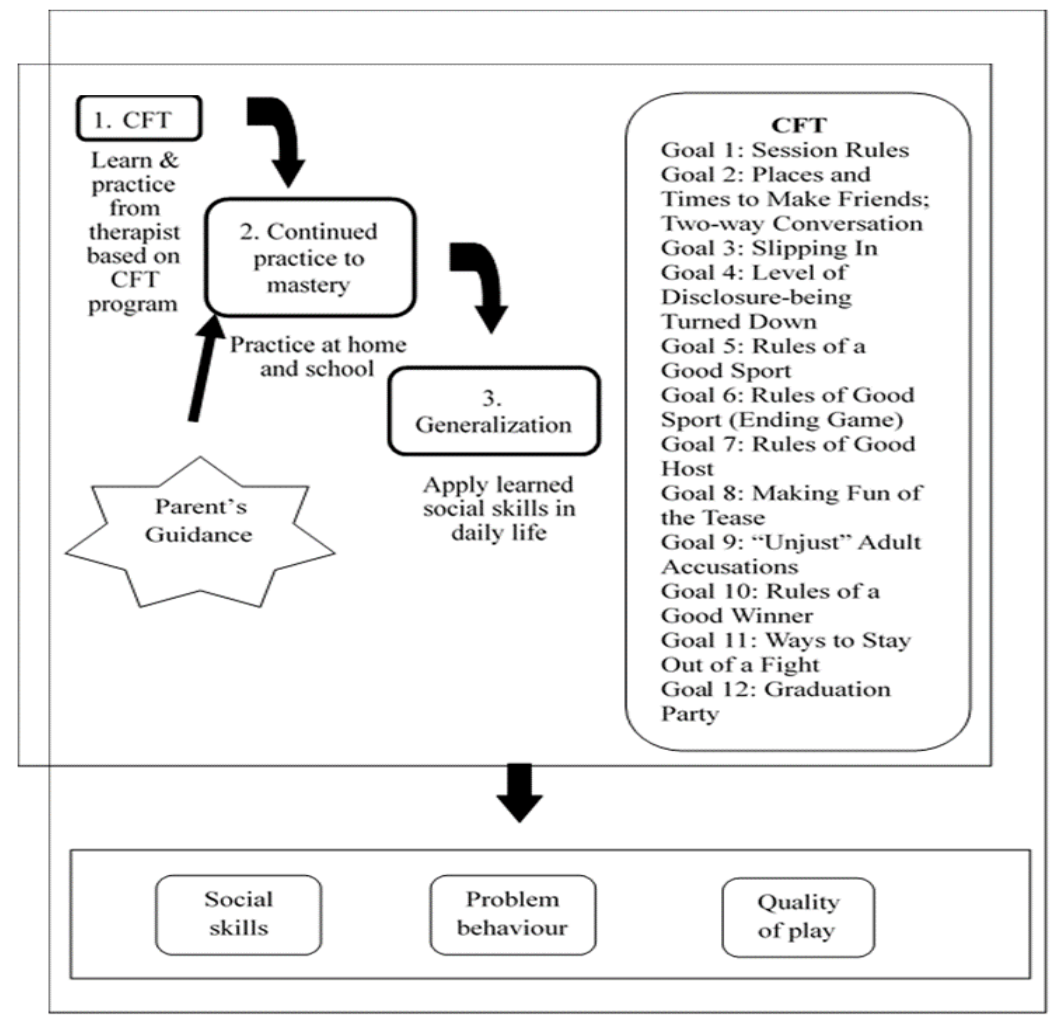

\subsection{Sampling}

Criterion sampling was used to recruit the participants for this research. It was chosen to optimize the evaluation of the treatment's effectiveness on this particular 
population (Palys, 2008; Patton, 1990). The 40 participants from the Klang Valley area fulfilled all four inclusion criteria to participate in this research, namely; the age of 7 to 12 years old, high functioning ASD children, able to communicate verbally in English, and acquired the concepts of losing and winning in social games. The number of sample size for this study was recruited based on the sample size justified by Murza et al. (2014) in which they recruited 25 participants specifically diagnosed with highfunctioning ASD adults. In this study, the researchers run a treatment to investigate the efficacy of the ACT \& Check Strategy intervention to improve inference generation when reading, metacognitive ability, social inference ability, and general reading comprehension in adults with high-functioning ASD (Murza et al., 2014).

In addition, the current study also refers to the sample size of other similar studies, such as the research conducted by Probst \& Glen (2011) in Germany where they have recruited 23 participants who had been diagnosed with ASD. The research was aimed at examining the effectiveness of TEACCH-based interventions studies for children with ASD as well as their parents (Probst \& Glen, 2011). Another similar research conducted was by Gantman et al. (2012). The researchers recruited around 17 children diagnosed with ASD to test the effectiveness of a caregiver-assisted social skills intervention known as PEERS for high-functioning adults with ASD (Gantman et al., 2012). In this study, the participants were divided into two separate classes. Later they were further divided into four groups. The first treatment was carried out at a secondary school in Selangor and the other 3 treatment groups were carried out at Universiti Putra Malaysia (UPM). Throughout the sessions, 9 participants withdrew as they were unable to commit to several of the 12 sessions program.

\subsection{Instruments}

This study used the Social Skills Rating System (SSRS) and the Quality of Play Questionnaire (QPQ) to measure social skills and quality of play. Both questionnaires were translated into Bahasa Malaysia and back-translated into English. The translated questionnaires were then validated by three professional lecturers at Universiti Putra Malaysia.

The SSRS questionnaire was developed by Gresham \& Elliot (1990) and consisted of 52-items in parent's form and 51-items in the teacher's form. Items in SSRS questionnaire were rated as "Never", "Sometimes", and "Very often". There are several subscales in this instrument and they are Cooperation, Assertion, Responsibility, Empathy, Self-control (subscales for Social Skills), and (Externalizing and Internalizing) subscales for Problem Behaviour (Frankel et al., 2010). It was reported that the authors developed SSRS using the content from literature searches and items selection by clinicians, parents, and other education professionals. The results showed a correlation of .75 between the Walker-McConnell Scale of Social Competence and School Adjustment and the try-out version of the SSRS Teacher Form (DiPerna et al., 2005; Gresham \& Elliot, 1990). Based on the result of the pilot test, the Social Skills scale reliability coefficients were .844 for the parent's form, and .837 for the teacher's form while the reliability coefficients for Problem Behaviour were .747 for the parent's form and .702 for the teacher's form.

The Quality of Play Questionnaire-Parent (QPQ) was developed by Frankel and Mintz (2008). This questionnaire consists of 19 items to measure the frequency and children's quality of play during their last play dates. It had three factor-based scales to measure the children's quality of play. These were conflict, engage, and disengage scales. The 
items were on a 4-point Likert-scale, ranging from "Not at all" (0), "Just a little" (1), "Pretty much" (2), and "Very much" (3). There were two open-ended items; item 18 and item 19. Item 18 required the parents to recall and report the frequency of their children being invited to play at another child's house as the only guest in the last month. Item 19 required the parents to recall and report the frequency of their children inviting another child to their house as the only guest to play in the last month (Frankel et al., 2010). The result of the test indicated a reliability coefficient of 842 for the Conflict factor-based scale, .658 for the Engage factor-based scale, and .736 for the Disengage factor-based scale.

\subsection{Data analysis}

Both descriptive and inferential statistics were utilized to conclude the findings on the effectiveness of CFT in enhancing social skills, quality of play, and reducing misbehaviours among children with ASD based on parents' and teachers' evaluations. In order to determine if there were significant increase in the variables studied after the intervention, paired sample t-tests were used the as data involved pairs of observations (pre-test and post-test) (Pham \& Jimenez, 2012).

\section{Result}

The 31 participants were between 7 to 12 years in age (Table 1) with 27 males $(87.1 \%)$ and 4 females $(12.9 \%)$.

Table 1: Frequency and Percentage of Respondents by Age

\begin{tabular}{ccc}
\hline Age & Frequency & Percent \\
\hline 7 & 8 & 25.8 \\
8 & 9 & 29.0 \\
9 & 5 & 16.1 \\
10 & 3 & 9.7 \\
11 & 3 & 9.7 \\
12 & 3 & 9.7 \\
\hline Total & 31 & 100.0 \\
\hline
\end{tabular}

The results from the paired sample t-test of social skills from the parents' evaluation (Table 2) revealed there was a significant increase in the mean scores of social skills from 32.45 in pre-test $(S D=10.45)$ to $52.45(S D=12.04)$ in post-test after CFT based on the parents' evaluation, $(t(30)=-8.266, p=.000)$. Calculation of effect size using Cohen's d indicated a very large effect size $(d=1.485)$. These results indicated, based on parents' evaluation, CFT did significantly improve the social skills of the 7 to 12-year-old children with ASD.

Table 2: Paired Sample Test of Social Skills (Pretest and Posttest) from the Teachers' Evaluation

\begin{tabular}{cccccc}
\hline Variable & Mean & SD & $\boldsymbol{t}$ & $\boldsymbol{d f}$ & Sig. (2-tailed) \\
\hline Social Skill (Pre-test) & 32.45 & 10.45 & - & 30 & .000 \\
Social Skill (Post-test) & 52.45 & 12.04 & -8.266 & & \\
\hline
\end{tabular}

Apart from the parents' evaluation on the children's social skills, teachers were also required to respond to both the pre-test and post-test. The results of the 
paired sample t-test of social skills from the teacher's evaluation (Table 3) also portrayed a similar pattern with a significant increase $(t(30)=-6.298, p=.000)$ in the scores of social skills of pre-test $(M=29.71, S D=8.98)$ compared to post-test $(M=41.55, S D=11.47)$. The effect size, Cohen's $d$, again indicated a very large effect size $(d=1.131)$.

Table 3: Paired Sample Test of Social Skills (Pre-test and Post-test) from the Teachers' Evaluation

\begin{tabular}{cccccc}
\hline Variable & Mean & $S D$ & $t$ & $d f$ & Sig. (2-tailed) \\
\hline Social Skill (Pre-test) & 29.71 & 8.98 & - & 30 & .000 \\
Social Skill (Post-test) & 41.55 & 11.47 & -6.298 & & \\
\hline
\end{tabular}

Besides social skills, this study also measured the changes in problem behaviours among the respondents (Table 4). The parents reported a significant decrease in problem behaviours of their children after going through CFT with a mean score of $5.55(S D=4.97)$ in the post-test, compared to $11.97(S D=3.49)$ in the pre-test, $(\mathrm{t}(30)=8.689, p=.000)$. Cohen's d indicated a large effect size $(d=1.561)$.

Table 4: Paired Sample Test of Problem Behaviour (Pre-test and Post-test) from the Parents' Evaluation

\begin{tabular}{cccccc}
\hline Variable & Mean & SD & $t$ & $d f$ & Sig. (2-tailed) \\
\hline Problem Behaviour (Pre-test) & 11.97 & 3.49 & - & 30 & .000 \\
Problem Behaviour (Post-test) & 5.55 & 4.97 & 8.689 & & \\
\hline
\end{tabular}

As shown in Table 5, the mean score of problem behaviours from the teachers' evaluation had similar trends. The initial pre-test mean of problem behaviour from the teachers' evaluation was $8.53(S D=4.38)$. However, after the 12 sessions of CFT, there is a significant decrease of problem behaviour with the post-test mean score from teachers' evaluation of $5.00(S D=4.63),(t(30)=4.023, p=.000)$. The effect size calculated using Cohen's $d$ indicated a medium effect size $(d=.723)$.

Table 5: Paired Sample Test of Problem Behaviour (Pre-test and Post-test) from the Teachers' Evaluation

\begin{tabular}{cccccc}
\hline Variable & Mean & $S D$ & $t$ & $d f$ & Sig. (2-tailed) \\
\hline Problem Behaviour (Pre-test) & 8.53 & 4.38 & - & 30 & .000
\end{tabular}

Problem Behaviour (Post-test) $\quad 5.00 \quad 4.63 \quad 4.023$

This study also compared the respondents' quality of play before and after the intervention using only the parents' evaluations (Table 6). Quality of play had three subscales; conflict, engaged and disengaged. The parents' evaluation results showed a significant decrease in the mean tests of conflict after the intervention $(M=2.74, S D=2.87)$ compared to before $(M=5.61, S D=2.74),(t(30)=3.949, p$ $=.000)$. There was also a significant reduction in the subscale of disengaged after the intervention, $(M=4.19, S D=2.10)$ compared to before $(M=5.52, S D=1.93)$, $(t(30)=3.474, p=.002)$. In addition, there was a significant increase in the subscale 
of engaged with the post-test mean score of $6.03(S D=2.21)$, compared to the pretest mean of $4.29(S D=2.16),(t(30)=-4.892, p=.000)$.

Table 6: Paired Sample Test of Social Skills (Pre-test and Post-test) from the Teachers' Evaluation

\begin{tabular}{lccccc}
\hline \multicolumn{1}{c}{ Variable } & Mean & SD & $t$ & $d f$ & Sig. (2 - tailed) \\
\hline Conflict (Pre-test) & 5.61 & 3.57 & 3.949 & 30 & .000 \\
Conflict (Post-test) & 2.74 & 2.87 & & & \\
\hline Engaged (Pre-test) & 4.29 & 2.16 & -4.892 & 30 & .000 \\
Engaged (Post-test) & 6.03 & 2.21 & & & \\
\hline Disengaged (Pre-test) & 5.52 & 1.93 & 3.474 & 30 & .000 \\
Disengaged (Post-test) & 4.19 & 2.10 & & & \\
\hline
\end{tabular}

\section{Discussion}

CFT was already explored by researchers outside of Malaysia as an intervention in friendship formation, but it has not been tried specifically for children with ASD in Malaysia. This study aimed to depict the suitability of using CFT for children with ASD in Malaysia by comparing the pre-test and post-test scores in social skills, quality of play, and problem behavior. The outcome measures were done by the teachers and parents of the children who participated in this study. The findings presented by the parents indicated some evidence that the social skills of children with ASD were significantly enhanced after they completed CFT. The findings from the teachers' report were consistent with the findings from the parents' report which concurred that there was a significant improvement in the social skills of children with ASD.

The CFT examined in the present study was associated with moderate increase in the frequency of hosted play obtained from the parents' evaluation results and reduced frequency in the time spent on electronic technology products such as I-pad, phone, computer, and television. This is consistent with the findings by Frankel et al. (2010) and Mandelberg, Laugeson, et al. (2014). One of the reasons for the improvement in ASD children's social skills in this study was because they learned about the appropriate places and times to make friends during the CFT program. According to Dekker et al. (2014), Matson and Wilkins (2009) and White et al. (2007), part of the reasons why most of the ASD children failed to make friends was due to the deficiency of certain knowledge and concepts of making friends. After the children had acquired enough knowledge on making friends, it was also found that they learned and kept practicing on how to have a two-way conversation with others in the second CFT session onwards. This is very interesting to note as most children with ASD show social communication impairment since toddlers. Hence, two-way communication was very significant for children with ASD to develop friendship, since social communication was one of the core struggle areas of ASD children (Dekker et al., 2014; Hansen et al., 2017).

One of the many reasons that make CFT program stood out from other social skill intervention program is the "slipping in" activity. The ASD children learned and practiced the appropriate steps in asking permission from their peers to participate during peer group play. This is an effective activity in helping ASD children to improve their social skills in making new friends through better play quality. Their old habit of "living in their own world" will potentially decrease which then leads to a better adjustment in life (Frankel \& Myatt, 2003). 
Another challenge faced by children with ASD is how to manage unfair adult accusations. This is a common situation in school as children with ASD continuously face difficulties in social skills and expressing themselves. This situation normally led to bigger issues for these children as they struggle with language and expressing their feelings, which then leads to the increase in their problem behaviors (Losh et al., 2012). Problem behaviors including aggressive and social withdrawal are believed to discourage interaction between children with ASD and other children (Major et al., 2017; Sullivan et al., 2019). In this study, the results indicated that there was a significant decrease in problem behavior among children with ASD which could perhaps be attributed to the skills acquired to properly manage their relationships with others, especially in tricky situations such as facing unfair adult accusations. This result is consistent with previous studies that showed similar decrease in the conflict with play dates, internalizing and externalizing symptoms, and increase in selfcontrol and self-esteem (Frankel et al., 2007; Frankel et al., 2010).

Based on the parents' evaluation in this current study, the children participants showed higher self-control and improved assertiveness. This is again consistent with results from past research which also indicated that children who received CFT treatment acquired lower scores in children's conflict and disengaged scale compared to children in the delayed treatment group (Frankel et al., 2010). One of the contributions to this finding was the content in the CFT sessions. Children in this study learned to set rules during the first session of the treatment to minimize the frequency of their problem behavior. Aligned with that, time-out and delayed playtime were used as punishment during the treatment process to reduce the problem behavior of children with ASD. On the other hand, reinforcements such as star and token system were applied in the treatment process to increase their motivation and appropriate behavior (Athens \& Vollmer, 2010; Payne \& Dozier, 2013; Querim et al., 2013). This helped indirectly to reduce the problem behaviors (Van Camp et al., 2000).

During the eighth session of the CFT, the children learned how to react towards peer teasing without causing tension and conflict. Children with ASD are already struggling with social skills that normally leads to an increase in the difficulties to make friends. They tend to have low self-esteem and will easily lose interest to socialize after being teased as they would compare themselves to their more capable peers (Neff, 2011). According to Williams et al. (2019) ASD students were self-aware of their difference and experienced challenges in being with the peer. However, parents in this study learned strategies to support and help their children when they were being teased. Parents' support and involvement were able to help the children to gain self-esteem needed to handle social teasing.

In addition, children in this study learned and practiced ways to stay out or avoid physical fights. This turned out to be one of the best solutions. They were also taught to identify the appropriate time and method to help their peers and friends who required help by reporting to other children or adults nearby to prevent them from getting into more trouble. Among other important things learned by the children in this study were the rules of good sports during and when ending a game, rules of good hosts, and rules of good winners that helped to improve their quality of play with peers. They learned and practiced on having sportsmanship and allowing others to have fun too during games and activities. They also learned to cooperate and work 
as a team and to suggest change of game when they were bored in an appropriate and more acceptable manner. Lastly, they also learned to acknowledge and praise other peers' behaviors during the rules of good sports session. This session was important as it built the children's confidence in making friends through games and activities. In previous studies, this has enabled them to create more satisfactory and continuing relationships with their playmates (Frankel \& Myatt, 2003). The findings on the children's achievement in the session on rules of good hosts and rules of good winners was supported by the findings from Lopes et al. (2013) and R. E. Adams et al. (2011). The children in the study learned about the importance and ways to become good hosts to serve, respect, and tolerate their guests.

\section{Limitation}

There are few limitations in this study. There will be no consistent types and number of group activities provided to the control group of this study as the participants came from different centres or schools. Besides that, this research was carried out in English with further explanation in Mandarin and Malay if needed.

\section{Suggestion}

There are three suggestions in implementing CFT. Firstly, a video recording of the first few homework carried out by the participants at home is recommended to be played at the end of the sessions. This will provide the parents with a clearer picture on how to carry out the tasks given as homework. Secondly, the researcher can provide clear guidance to the parents using a real case study to maximize the results gained from the homework given. Lastly, the parents should be informed beforehand to prepare the friend list so that they were more prepared with the homework. For further study, it is proposed that this intervention is extended to children with other learning disabilities. Researchers should also consider having a larger sample during the recruitment as the long duration involved, and the additional homework given to parents and children might cause several participants to drop out mid-way. Thirdly, as CFT is a parent inclusive intervention program, it is suggested that parental experience in CFT be explored in more depth. CFT can also be introduced to government and private special needs schools in Malaysia. To deliver CFT effectively for children with ASD; teachers need to be trained to conduct CFT, the schools need to ensure children with ASD meet the requirement as stated in CFT through screening sessions, and parents' cooperation and commitment should be ascertained beforehand to ensure the success of the program.

\section{Conclusion}

The findings indicated that CFT was significantly impactful in enhancing social skills of 7 to 12-year-old children with ASD. Both parents and teachers reported significant increase in the level of social skills among children with ASD who participated in CFT. It can be concluded that CFT has a high potential to be adopted as an intervention programme for high functioning ASD children in Malaysia. It is empirically proven that CFT is a program that can be a benchmark in Malaysia as one of the mediums in helping children with ASD towards a better future. CFT also serves as one of the tools to empower parents in assisting children with ASD in enhancing their social competence. The features of children with ASD who lack social ability should not be a barrier for them in making new 
friends and maintaining friendships in the future. Therefore, the effort in helping them should be continuously implemented in this country.

\section{References}

Adams, D., Harris, A., \& Jones, M. S. (2017). Exploring teachers' and parents' perceptions on social inclusion practices in Malaysia. Pertanika Journal of Social Sciences and Humanities, 25(4), 1721-1738.

Adams, R. E., Bruce Santo, J., \& Bukowski, W. M. (2011). The presence of a best friend buffers the effects of negative experiences. Developmental Psychology, 47(6), 17861791.

Alallawi, B., Hastings, R. P., \& Gray, G. (2020). A systematic scoping review of social, educational, and psychological research on individuals with Autism Spectrum Disorder and their family members in Arab countries and cultures. Review Journal of Autism and Developmental Disorders. https://doi.org/10.1007/s40489-020-00198-8

Amar, H. S. S. (2008). Meeting the needs of children with disability in Malaysia. Medical Journal of Malaysia, 63(1), 1-3.

Athens, E. S., \& Vollmer, T. R. (2010). An investigation of differential reinforcement of alternative behavior without extinction. Journal of Applied Behavior Analysis, 43(4), 569-589. https://doi.org/10.1901/jaba.2010.43-569

Baron-Cohen, S., O'Riordan, M., Stone, V., Jones, R., \& Plaisted, K. (1999). Recognition of Faux Pas by normally developing children and children with Asperger Syndrome or high- functioning Autism. Journal of Autism \& Developmental Disorders, 29(5), 407-418. https://doi.org/10.1053/j.otsm.2009.08.002

Bauminger, N., Shulman, C., \& Agam, G. (2003). Peer interaction and loneliness in high functioning children with autism. Journal of Autism and Developmental Disorders, 33(5), 489-507.

Bauminger, N., Shulman, C., \& Agam, G. (2004). The link between perceptions of self and of social relationships in high-functioning children with autism. Journal of Developmental and Physical Disabilities, 16(2), 193-214. https://doi.org/10.1023/B:JODD.0000026616.24896.c8

Bellini, S., \& Akullian, J. (2007). A meta-analysis of video modeling and video selfmodeling interventions for children and adolescents with Autism Spectrum Disorders. Exceptional Children. https://doi.org/10.1177/001440290707300301

Calder, L., Hill, V., \& Pellicano, E. (2013). "Sometimes I want to play by myself": Understanding what friendship means to children with autism in mainstream primary schools. Autism: The International Journal of Research and Practice, 17(3), 296316. https://doi.org/10.1177/1362361312467866

Chang, Y. C., Shih, W., \& Kasari, C. (2016). Friendships in preschool children with autism spectrum disorder: What holds them back, child characteristics or teacher behavior? Autism, 20(1), 65-74. https://doi.org/10.1177/1362361314567761

Clark, K. (2016). Prizant, B.M. \& Field-Meyers, T. (2015). Uniquely Human: A Different Way of Seeing Autism. New York, NY: Simon \& Schuster. ISBN: 978-1-4767-7623-1. 256 pp. (Hardcover). Family and Consumer Sciences Research Journal, 44(4), 472-475. https://doi.org/10.1111/fcsr.12167

Cook, J. L., \& Cook, G. (2009). Child development: Principles and perspectives (2nd ed.). Pearson Inc.

Crone, R. M., \& Mehta, S. S. (2016). Parent training on generalized use of behavior analytic strategies for decreasing the problem behavior of children with Autism Spectrum Disorder: A data-based case study. Education and Treatment of Children, 39(1), 64-94.

Dekker, V., Nauta, M. H., Mulder, E. J., Timmerman, M. E., \& de Bildt, A. (2014). A randomized controlled study of a social skills training for preadolescent children with Autism Spectrum Disorders: generalization of skills by training parents and teachers? BMC Psychiatry, 14(1), 189. https://doi.org/10.1186/1471-244X-14-189 
Demopoulos, C., Hopkins, J., \& Lewine, J. D. (2016). Relations between nonverbal and verbal social cognitive skills and complex social behavior in children and adolescents with Autism. Journal of Abnormal Child Psychology, 44(5), 913-921. https://doi.org/10.1007/s10802-015-0082-z

DiPerna, J. C., Volpe, R. J., \& Elliott, S. N. (2005). A model of academic enablers and mathematics achievement in the elementary grades. Journal of School Psychology, 43(5), 379-392. https:// doi.org/10.1016/j.jsp.2005.09.002

Dunfield, K. A., Best, L. J., Kelley, E. A., \& Kuhlmeier, V. A. (2019). Motivating moral behavior: Helping, sharing, and comforting in young children with Autism Spectrum Disorder. Frontiers in Psychology, 10(JAN), 1-12. https://doi.org/10.3389/fpsyg.2019.00025

Flavell, J. H., \& Miller, P. H. (1998). Social cognition. In R. S. Damon, W., Lerner, R. M., Kuhn, D., Siegler (Ed.), Handbook of Child Psychology, Vol. 2: Cognition, Perception, and Language (6th ed., pp. 851-898). Wiley.

Fombonne, E. (2009). Epidemiology of Pervasive Developmental Disorders. Pediatric Research, 65(6), 591-598. https:// doi.org/10.1203/PDR.0b013e31819e7203

Frankel, F., Myatt, R., \& Feinberg, D. (2007). Parent-assisted friendship training for children with autism spectrum disorders: Efects of psychotropic medication. Child Psychiatry and Human Development, 37(4), 337-346. https://doi.org/10.1007/s10578007-0053-x

Frankel, F., Myatt, R., Sugar, C., Whitham, C., Gorospe, C. M., \& Laugeson, E. (2010). A randomized controlled study of parent-assisted children's friendship training with children having Autism Spectrum Disorders. Journal of Autism and Developmental Disorders, 40(7), 827-842. https://doi.org/10.1007/s10803-009-0932-z

Frankel, F., \& Myatt, R. (2003). Children's friendship training. routledge.

Gantman, A., Kapp, S. K., Orenski, K., \& Laugeson, E. A. (2012). Social skills training for young adults with high-functioning Autism Spectrum Disorders: A randomized controlled pilot study. Journal of Autism and Developmental Disorders, 42(6), 1094-1103. https://doi.org/10.1007/s10803-011-1350-6

Gresham, F., \& Elliot, S. N. (1990). Social Skills Rating System. American Guidance Service.

Hale, C. M., \& Tager-Flusberg, H. (2005). Social communication in chidren with Autism: The relationship between theory of mind and discourse development. Autism, 9(2), 157-178. https://doi.org/10.1177/1362361305051395

Hansen, S. G., Frantz, R. J., Machalicek, W., \& Raulston, T. J. (2017). Advanced social communication skills for young children with Autism: A systematic review of singlecase intervention studies. Review Journal of Autism and Developmental Disorders, 4(3), 225-242. https://doi.org/10.1007/s40489-017-0110-8

Hill, T. L., Gray, S. A. O., Baker, C. N., Boggs, K., Carey, E., Johnson, C., Kamps, J. L., \& Enrique, V. R. (2017). A pilot study examining the effectiveness of the PEERS Program on social skills and anxiety in adolescents with Autism Spectrum Disorder. Journal of Developmental and Physical Disabilities, 29(5), 797-808. https:// doi.org/10.1007/s10882-017-9557-x

Kazemi, F., \& Abolghasemi, A. (2019). Effectiveness of play-based empathy training on social skills in students with autistic spectrum Disorders. Archives of Psychiatry and Psychotherapy, 21(3), 71-76. https:// doi.org/10.12740/APP/105490

Kent-Walsh, J., Murza, K. A., Malani, M. D., \& Binger, C. (2015). Effects of communication partner instruction on the communication of individuals using AAC: A metaanalysis. Augmentative and Alternative Communication, 31(4), 271-284. https://doi.org/10.3109/07434618.2015.1052153

Laugeson, E. A., Paley, B., Schonfeld, A. M., Erika, M., Frankel, F., \& O'Connor, M. J. (2007). Adaptation of the Children's sriendship Training Program for children with Fetal Alcohol Spectrum Disorders. Child \& Family Behavior Therapy, 29(3), 37-41. https://doi.org/10.1300/J019v29n03 
Laugeson, E. A., Frankel, F., Gantman, A., Dillon, A. R., \& Mogil, C. (2012). Evidencebased social skills training for adolescents with autism spectrum disorders: The UCLA PEERS program. Journal of Autism and Developmental Disorders, 42(6), 10251036. https://doi.org/10.1007/s10803-011-1339-1

Locke, J., Kasari, C., \& Wood, J. J. (2014). Assessing social skills in early elementary-aged hildren With Autism Spectrum Disorders: The social skills Q-Sort. Journal of Psychoeducational Assessment, 32(1), 62-76. https://doi.org/10.1177/0734282913485543

Lopes, V. P., Gabbard, C., \& Rodrigues, L. P. (2013). Physical activity in adolescents: Examining influence of the best friend dyad. Journal of Adolescent Health, 52(6), 752756. https://doi.org/10.1016/j.jadohealth.2012.12.004

Losh, M., Martin, G. E., Klusek, J., Hogan-Brown, A. L., \& Sideris, J. (2012). Social Communication and Theory of Mind in Boys with Autism and Fragile X Syndrome. In Frontiers in Psychology (Vol. 3).

Lovaas, O. I., Smith, T., \& McEachin, J. J. (1989). Clarifying comments on the young autism study: reply to Schopler, Short, and Mesibov. Journal of Consulting and Clinical Psychology, 57(1), 165-167. https:// doi.org/10.1037/0022-006X.57.1.165

Lovaas, O. I., Koegel, R., Simmons, J. Q., \& Long, J. S. (1973). Some generalization and follow-up measures on autistic children in behavior therapy. Journal of Applied Behavior Analysis, 6(1), 131-165. https://doi.org/10.1901/jaba.1973.6-131

Major, S., Seabra-Santos, M. J., \& Albuquerque, C. P. (2017). Validating the preschool and kindergarten behavior scales-2: Preschoolers with Autism Spectrum Disorders. Research in Developmental Disabilities, 65, 86-96. https://doi.org/10.1016/j.ridd.2017.04.008

Mandelberg, J., Frankel, F., Cunningham, T., Gorospe, C., \& Laugeson, E. A. (2014). Longterm outcomes of parent-assisted social skills intervention for high-functioning children with autism spectrum disorders. Autism, 18(3), 255-263. https://doi.org/10.1177/1362361312472403

Mandelberg, J., Laugeson, E. A., Cunningham, T. D., Ellingsen, R., Bates, S., \& Frankel, F. (2014). Long-term treatment outcomes for parent-assisted social skills training for adolescents with autism spectrum disorders: The UCLA PEERS program. Journal of Mental Health Research in Intellectual Disabilities, 7(1), 45-73. https:// doi.org/10.1080/19315864.2012.730600

Matson, J. L., \& Wilkins, J. (2009). Psychometric testing methods for children's social skills. Research in Developmental Disabilities, 30(2), 249-274. https://doi.org/10.1016/j.ridd.2008.04.002

Mazza, M., Mariano, M., Peretti, S., Masedu, F., Pino, M. C., \& Valenti, M. (2017). The role of theory of mind on social information processing in children with Autism Spectrum Disorders: A mediation analysis. Journal of Autism and Developmental Disorders, 47(5), 1369-1379. https:// doi.org/10.1007/s10803-017-3069-5

McConnell, S. R. (2002). Interventions to facilitate social interaction for young children with Autism: Review of available research and recommendations for educational intervention and future research. Journal of Autism and Developmental Disorders, 32(5), 351-372. https://doi.org/10.1023/A:1020537805154

Montroy, J. J., Bowles, R. P., Skibbe, L. E., \& Foster, T. D. (2014). Social skills and problem behaviors as mediators of the relationship between behavioral self-regulation and academic achievement. Early Childhood Research Quarterly, 29(3), 298-309. https://doi.org/10.1016/j.ecresq.2014.03.002

Morelli, S. A., Lieberman, M. D., \& Zaki, J. (2015). The emerging study of positive empathy. Social and Personality Psychology Compass, 9(2), 57-68. https://doi.org/10.1111/spc3.12157

Murza, K. A., Nye, C., Schwartz, J. B., Ehren, B. J., \& Hahs-Vaughn, D. L. (2014). A randomized controlled trial $\mathrm{o}$ an inference generation strategy intervenion for adults 
with high- functioning Autism Spectrum Disorder. American Journal of SpeechLanguage Pathology, 23, 461-473. https://doi.org/10.1044/2014

Nevin, J. A., \& Grace, R. C. (2000). Behavioral momentum and the law of effect. Behavioral and Brain Sciences, 23(1), 73-130. https://doi.org/10.1017/S0140525X00002405

Palys, T. (2008). Purposive sampling. In L.M. Given (Ed.), The Sage encyclopedia of qualitative research methods (Vol. 1\& 2) (pp. 726-727). Sage Publications Inc.

Patton, M. Q. (1990). Qualitative evaluation and research methods. In Sage Publication (2nd ed.). https:// doi.org/10.4135/9781473913882.n3

Payne, S. W., \& Dozier, C. L. (2013). Positive reinforcement as treatment for problem behavior maintained by negative reinforcement. Journal of Applied Behavior Analysis, 46(3), 699-703. https://doi.org/10.1002/jaba.54

Petrina, N., Carter, M., \& Stephenson, J. (2014). The nature of friendship in children with autism spectrum disorders: A systematic review. Research in Autism Spectrum Disorders, 8(2), 111-126. https:/ / doi.org/10.1016/j.rasd.2013.10.016

Pham, T. V., \& Jimenez, C. R. (2012). An accurate paired sample test for count data. Bioinformatics, 28(18), 596-602. https://doi.org/10.1093/bioinformatics/bts394

Pop, C. A., Pintea, S., Vanderborght, B., \& David, D. O. (2014). Enhancing play skills, engagement and social skills in a play task in ASD children by using robot-based interventions. A pilot study. Interaction Studies Interaction Studies Social Behaviour and Communication in Biological and Artificial Systems, 15(2), 292-320. https://doi.org/10.1075/is.15.2.14pop

Probst, P., \& Glen, I. (2011). TEACCH-based interventions for families with children with Autism Spectrum Disorders: Outcomes of a parent group training study and a homebased child-parent training single case study. Life Span and Disability, 14(2), 111-138. https:// doi.org/2012-32730-003

Querim, A. C., Iwata, B. A., Roscoe, E. M., Schlichenmeyer, K. J., Ortega, J. V., \& Hurl, K. E. (2013). Functional analysis screening for problem behavior maintained by automatic reinforcement. Journal of Applied Behavior Analysis, 46(1), 47-60. https://doi.org/10.1002/jaba.26

Ray-Kaeser, S., Thommen, E., Baggioni, L., \& Stanković, M. (2017). Play in children with Autism Spectrum and other developmental disorders. In Play Development in Children with Disabilities (pp. 137-146). De Gruyter. https://doi.org/10.1515/9783110522143

Reichow, B., Steiner, A. M., \& Volkmar, F. (2012). Cochrane review: social skills groups for people aged 6 to 21 with autism spectrum disorders (ASD). Cochrane Database of Systematic Reviews, 7, 266-315. https://doi.org/10.1002/14651858.CD008511.pub2

Salter, K., Beamish, W., \& Davies, M. (2016). The effects of child-centered play therapy (CCPT) on the social and emotional growth of young Australian children with Autism. International Journal of Play Therapy, 25(2), 78-90. https://doi.org/10.1037/pla0000012

Scheeren, A. M., Koot, H. M., \& Begeer, S. (2020). Stability and change in social interaction style of children with Autism Spectrum Disorder: A 4-year follow-up study. Autism Research, 13(1), 74-81. https://doi.org/10.1002/aur.2201

Schohl, K. A., Van Hecke, A. V., Carson, A. M., Dolan, B., Karst, J., \& Stevens, S. (2014). A replication and extension of the PEERS intervention: Examining effects on social skills and social anxiety in adolescents with autism spectrum disorders. Journal of Autism and Developmental Disorders, 44(3), 532-545. https://doi.org/10.1007/s10803013-1900-1

Sigman, M., \& Ruskin, E. (1999). Continuity and change in the social competence of children with Autism, Down Syndrome, and Developmental Delays. Monographs of the Society for Research in Children Development, 64(114).

Skafle, I., Nordahl-Hansen, A., \& Øien, R. A. (2020). Short Report: Social Perception of High School Students with ASD in Norway. Journal of Autism and Developmental 
Disorders, 50(2), 670-675. https:// doi.org/10.1007/s10803-019-04281-w

Sullivan, M. O., Gallagher, L., \& Heron, E. A. (2019). Gaining insights into aggressive behaviour in Autism Spectrum Disorder using latent profile analysis. Journal of Autism and Developmental Disorders, 49(10), 4209-4218. https://doi.org/10.1007/s10803-019-04129-3

Tse, J., Strulovitch, J., Tagalakis, V., Meng, L., \& Fombonne, E. (2007). Social skills training for adolescents with Asperger syndrome and high-functioning autism. Journal of Autism and Developmental Disorders, 37(10), 1960-1968. https://doi.org/10.1007/s10803-006-0343-3

Van Camp, C. M., Lerman, D. C., Kelley, M. E., Contrucci, S. A., \& Vorndran, C. M. (2000). Variable-time reinforcement schedules in the treatment of socially maintained problem behavior. Journal of Applied Behavior Analysis, 33(4), 545-557. https://doi.org/10.1901/jaba.2000.33-545

Varley D., Wright B., Cooper C., Marshall D., Biggs K., Ali S., Chater T., Coates E., Gilbody S., Cuesta G. G., Kingsley E., Couteur A.L., McKelvey A., Shephard N., Teare D.(2019).Investigating Social Competence and Isolation in children with Autism taking part in LEGObased therapy clubs In School Environments (I-SOCIALISE): study protocol. BMJ Open 2019 doi:10.1136/ bmjopen

Weiss, M. J., \& Harris, S. L. (2001). Teaching social skills to people with Autism. Behavior Modification, 25(5), 785-802. https:// doi.org/10.1177/0145445501255007

White, S. W., Albano, A. M., Johnson, C. R., Kasari, C., Ollendick, T., Klin, A., Oswald, D., \& Scahill, L. (2010). Development of a cognitive-behavioral intervention program to treat anxiety and social deficits in teens with high-functioning Autism. Clinical Child and Family Psychology Review, 13(1), 77-90. doi:10.1007/s10567-009-0062-3

White, S. W., Keonig, K., \& Scahill, L. (2007). Social skills development in children with autism spectrum disorders: A review of the intervention research. Journal of Autism and Developmental Disorders, 37(10), 1858-1868. doi:10.1007/s10803-006-0320-x

Williams, E. I., Gleeson, K., \& Jones, B. E. (2019). How pupils on the Autism Spectrum make sense of themselves in the context of their experiences in a mainstream school setting: A qualitative metasynthesis. Autism, 23(1), 8-28. https://doi.org/10.1177/1362361317723836

Woolfolk, A. (2015). Educational psychology (13th ed.). Pearson Education Limited.

Yamada, T., Miura, Y., Oi, M., Akatsuka, N., Tanaka, K., Tsukidate, N., Yamamoto, T., Okuno, H., Nakanishi, M., Taniike, M., Mohri, I., \& Laugeson, E. A. (2020). Examining the treatment efficacy of PEERS in Japan: Improving social skills among adolescents with Autism Spectrum Disorder. Journal of Autism and Developmental Disorders, 50(3), 976-997. https://doi.org/10.1007/s10803-019-04325-1 